\title{
Optimization of Recyclables Collection Processes
}

\author{
${ }^{1}$ Milorad Vidovic, ${ }^{2}$ Branislava Ratkovic* ${ }^{3}$ Nenad Bjelic, ${ }^{4}$ Drazen Popovic \\ 1,2,3,4 University of Belgrade, Faculty of transport and traffic engineering, Vojvode Stepe 305, Belgrade, Serbia \\ ${ }^{1}$ mvidovic@sf.bg.ac.rs ${ }^{2}$ b.ratkovic@sf.bg.ac.rs ${ }^{3}$ n.bjelic@sf.bg.ac.rs ${ }^{4}$ d.popovic@sf.bg.ac.rs
}

\begin{abstract}
In the last decade environmental concerns, legislative measures and growing public awareness about the environmental consequences of waste disposal and extraction of natural resources have led to an increase in recycling and reuse efforts. However, both recycling and reuse require appropriate reverse logistics network structure, as well as adequate realization of logistics processes in such a network. The focus of this paper is to consider the problem of waste materials collection processes, which comprises pick-up recyclables from collection points and transferring them to a recycling facility. Because the recyclables value is relatively low, realization of reverse logistics processes, particularly those related to its collection, introduces the relatively high costs. On the other side, efficient and cost effective recycling in treatment facilities requires adequate supply with collected recyclables. Therefore, having in mind experience from forward supply chain management, and potentials of joint coordination of transportation and inventory decisions, this research introduces planning methodology to optimization of recyclable collection processes. That is, our intention is to propose modeling approach that simultaneously considers collection vehicles scheduling, and recyclables inventories optimization. Furthermore, as some of recyclables could be hazardous materials, risk minimizing criterion has been also considered.
\end{abstract}

Keywords: reverse logistics, collection, inventories routing, risk minimizing

\section{Introduction}

In the last decade of the XX century, environmental concerns, legislative measures and growing public awareness about the environmental consequences of waste disposal and extraction of natural resources have led to an increase in recycling and reuse efforts. Especially, the growth on environmental policy, related to end of life products (EOL), has favored the development of reverse logistics systems. The objectives of reverse logistics system are to reduce the total distance of transportation, increase the quantities of EOL products collected, reduce the amount of EOL products carried to treatment facilities inefficiently and to connect reverse logistics to forward logistics in an efficient way Umeda et al (2003).

A key element of reverse logistics system is the collection or acquisition of used product discarded by last owners or consumers. It is the first and crucial activity of reverse logistics system that triggers the others activities such as repairing, refurbishing, remanufacturing, cannibalization and recycling (Thierry et al 1995). In recent years, a significant amount of work has been focused on the design and optimization of logistics systems with reverse flows (Bostel et al 2005). Most papers dealing with collection issues in reverse logistics are focused on vehicle routing problems and its applications on specific

${ }^{*}$ Corresponding Author 
problems. Beullens et al. (2001) presents a survey about collection and vehicle routing issues in reverse logistics. Teixeira et al. (2004) describes a study of planning vehicle routes for the collection of three types of recyclable waste in Portugal. Poot et al. (2002) present several non-traditional constraints of real-life vehicle routing problems such as multiple capacity constraints, vehicle type constraints, region constraints, served first or last constraint, and multiple time windows. Blanc et al. (2004) present a network redesign problem for a case of LPG-tanks in Netherlands. They applied an integer-programming model to minimize the total costs and to determine the optimal number and the geographic location of the degassing locations. Krikke et al. (2008) discussed an application of remote monitoring of inventory levels in reverse logistics to improve the collection efficiency of the mandatory collection of dismantled materials. Recently, Aras et al. (2008) formulate mixed-integer nonlinear collection center location problem (CCLP) to ûnd both the optimal locations of a predetermined number of collection centers and the optimal incentive values for different return types.

However, a part of reverse logistics flows are related to dangerous, or obnoxious substances that are, while transported and stored, represent risk to the environment, individuals or properties. In that case establishing logistic networks require appropriate approaches that can give solutions while respecting risk as a one of criterions. There are two concepts dealing with risk in logistics processes. Risk minimization concepts, both in facility location and transportation context are considered by numerous researches in the last thirty year, and for more detailed insight in this area, to the interested reader we recommend book chapter of Erkut et al. (2007). Concepts and approaches to risk equalizing have been also subject of intensive research during last three decades. For example, Keeney (1980) expresses equity as the magnitude of the largest difference in the level of risk among a fixed set of individuals. Morrell (1984) discusses an equitable solution to the problem of citing hazardous materials (HM) dump sites. Approach to the modeling of risk, equity and efficiency in facility location and transportation of HM, can be found in Current J., Ratick S. (1995). Jayaraman et al. (2003) formulate a MILP model to determine an efficient strategy for the reverse logistics operations of HM. These products currently located at retail outlets are ûrst sent to collection facilities and then transshipped to refurbishing sites.

Focus of the research presented here is the problem of simultaneously defining inventory levels, and transport schedule under criterions of risk minimizing or equalizing, in case when locations of collection sites and recycling facility (return point) are known. In this way problem is similar to integrated Inventory Routing Problem (IRP), where the idea is to simultaneously solve problems of optimal quantity and time of delivery of goods, as well as the problem of optimal scheduling of vehicles. However, here, the objective of finding balance between inventory and transport costs is widened by introducing additional, risk criterions, transforming the IRP problem into the one kind of Reverse Logistics Inventory Routing Problems Under Risk (RLIRPUR).

Having on mind the objective, the remainder of the paper is organized as follows. In section two the characteristics of recyclables collection systems, as well as risk minimizing, concepts are presented. Section three presents the optimization model for the RLIRPUR, while the section four gives some computational results from the numerical example. Finally, some concluding remarks are given in section five.

\section{Collection systems for recyclable materials}

The establishment of networks to carry out reverse logistics activities is crucial to ensure the efficient recovery value from different EOL products. However, although EU Directives which are devoted to different types of EOL products (End-of life vehicles directive, Waste electrical and electronic equipment directive,...) sets some standards, they don't define detailed network structure, nor reverse logistics processes technology. Therefore, Directives implementation and reverse logistics networks establishing require additional instructions and specific directions.

In general, reverse logistics networks have few levels. The initial one is the last owner of EOL product (waste producer), which is a network source. Last owners should be provided with the ability of disposing EOL products to the second level which is collection point. A number of different systems have been implemented to collect recyclables from the 
general waste stream. The two main categories of collection systems are "curbside collection", and "drop-off centres". The "curbside collection" is the concept where the collection points are located close to a single-family as well as multi-family house. Curbside collection encompasses different systems, which differ mostly on where in the process the recyclables are sorted and cleaned. The main categories are mixed waste collection, commingled recyclables and source separation. Drop-off collection centres require the EOL product last owner to carry the recyclates to a central location, either an installed or mobile collection station or the reprocessing plant itself. They are the easiest type of collection to establish, but suffer from low and unpredictable throughput. Application some of these systems lie along the spectrum of trade-off between public convenience and government ease and expense. For some types of EOL products, particularly for the case of dangerous waste, collecting sites and facilities should be certified (Endof life vehicles, used motor oil,...).

After used products are consolidated at collection facilities, they are shipped to the next level of reverse logistics network. Depending on the kind of waste, or recyclables next level can be sorting, disassembling, transfer facility, or even, recycling plant. In any case, the ûnal destination of the returns is either remanufacturing or recycling facility, where product recovery takes place, or disposal sites.
In this research we consider simple two level reverse logistics network consists of set of drop-off collection locations, at the first level, and one recycling plant at the second, as it is shown in Figure 1.

Supplying recycling facility with collected recyclables is normally accomplished by a fleet of trucks. Recycling process requires that products are returned in the best possible condition in quantity and supply frequency which provide continuity in the treatment process. Finally, the products need to be transported in a cost-efficient and environmentally friendly way to the treatment facilities of the reverse logistics network.

The cost efficiency in RLIRPUR is related only to the transportation cost, because of low value of recyclables, providing continuity of the recycling process requires adequate supply regard to its quantity and frequency, having always in mind that transport costs are lower when using vehicle of bigger capacity with lesser frequency. However, while low valuable recyclables tend to increase inventory level in the system, higher risk imposed by larger quantities of hazardous recyclables require decreasing average inventories level in all network nodes, as well as making trade-off between frequency of supplies and quantity of recyclables in each supply. Therefore, it becomes obvious that solving RLIRPUR means finding balance between providing continuity of recycling process, transportation costs, inventory level, and risk imposed by transporting and storing hazardous recyclables.

Figure 1. Two level reverse logistics network for collection and treatment of recyclables

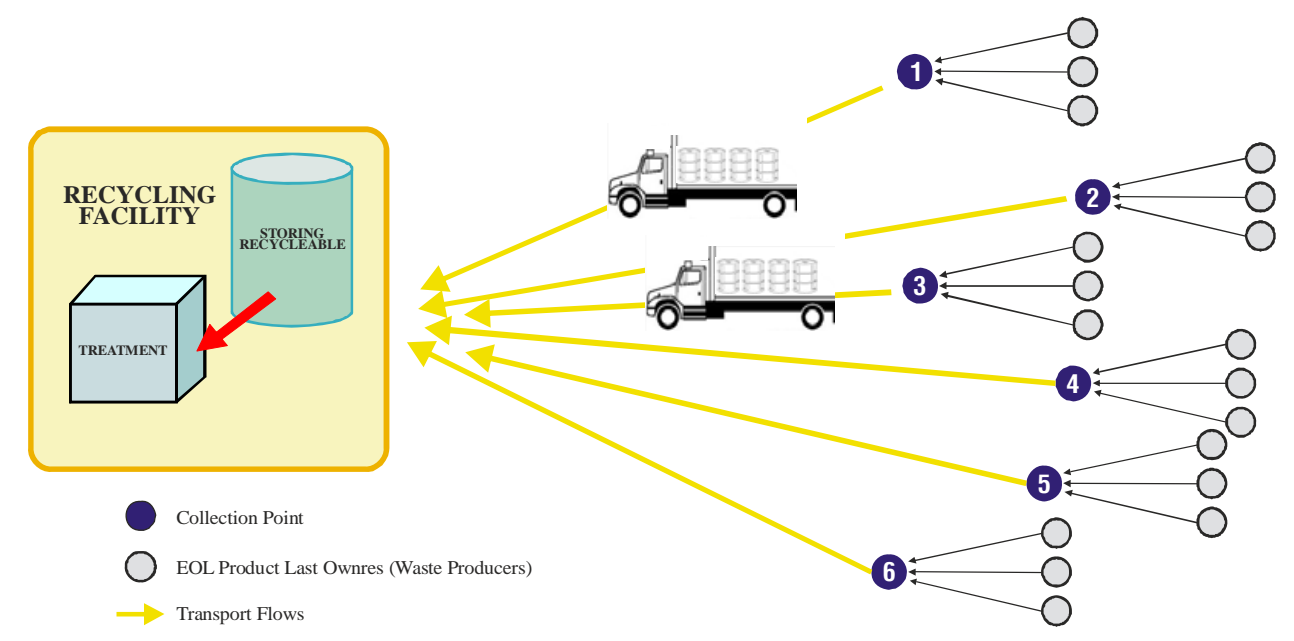


In the context of HM, risk is a measure of the probability and severity of harm to an exposed receptor due to potential undesired events. The exposed receptor can be a person, the environment, or properties in the vicinity. Widely used assumption that aids estimation of consequences is that in the event of an accident the HM has a radius of spread that depends on physical and chemical properties of the substance in question. If $\lambda$ represents the radius of spread, receptors within the boundary of a circle with a radius could potentially be affected. For travel on a link, we could speak of a whole $\lambda$ neighborhood that is endangered. The $\lambda$ neighborhood is a concept (Figure 2) developed by Batta and Chiu (1988), and it is used when calculating risk in our model. Two types of risk need to be taken into account in integrating inventory level at storing sites and routing decisions pertaining to $\mathrm{HM}$ recyclables supply: transport risk $\mathrm{R}_{\mathrm{ij}}^{\mathrm{T}}$ on the link (i,j), and storing facility $\mathrm{j}$ risk $\mathrm{R}_{\mathrm{j}}^{\mathrm{F}}$.

Figure 2. $\lambda$-neighborhood concept

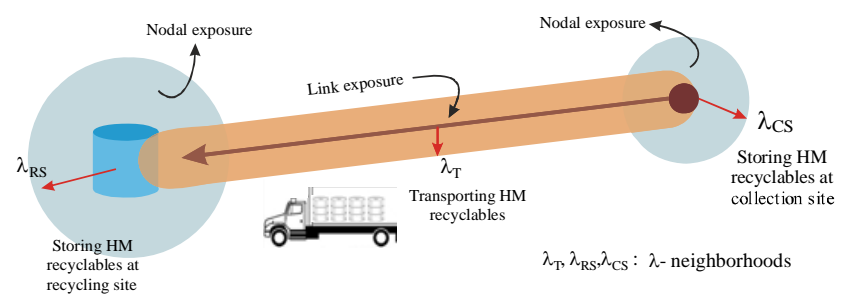

Given a risk function $f(x, y)$ over the $\lambda$ neighborhood of the area of $A_{1}$ after describing it in a Cartesian coordinate system, risk $\mathrm{R}_{\mathrm{A}_{\lambda}}$ in the exposed area can be computed as:

$$
\mathrm{R}_{\mathrm{A}_{\lambda}}=\iint_{\mathrm{A}_{\lambda}} \mathrm{f}(\mathrm{x}, \mathrm{y}) \mathrm{dxdy}
$$

Although in most cases, the $\mathrm{HM}$ has a radius of spread (r) proportional to the third root of its quantity (Q), in this research it is assumed that the radius of spread in case of storing facility is a function of the square root of quantity i.e. $r \cong \sqrt[2]{\mathrm{Q}}$, similarly to the idea deployed by Current and Ratick
(1995). This approximation gives opportunity to easily calculate risk $R_{j}^{F}$ imposed by storing facility $j$ as a area of circle of the radii $\sqrt{\mathrm{Q}_{\mathrm{j}}}$

$\mathrm{R}_{\mathrm{j}}^{\mathrm{F}}=\alpha \pi \mathrm{Q}_{\mathrm{j}}$

where

$\alpha$ is a density of exposed receptors (population, properties,...)

$Q_{j} \quad$ quantity of $\mathrm{HM}$ recyclables in storing facility $\mathrm{j}$

In the case of transport risk computation radius of spread is consequence of the vehicle capacity. When assume reasonable use of vehicles which are loaded close to its capacity $\mathrm{q}_{\mathrm{k}^{\prime}}$ imposing radius of spread of $r_{k^{\prime}}$ then transport risk $R_{i j}^{T}$ on the link $(i, j)$ in each trip can be calculated as:

$\mathrm{R}_{\mathrm{ij}}^{\mathrm{T}}=\alpha\left(2 \mathrm{r}_{\mathrm{k}} \mathrm{d}_{\mathrm{ij}}+\pi \mathrm{r}_{\mathrm{k}}^{2}\right)$

$r_{k} \quad$ radius of spread which corresponds to the vehicle of capacity of $\mathrm{q}_{k}$

$d_{i j} \quad$ length of the link (i,j)

Note that the approach used in risk computation does not respect accident probability which corresponds to the so called "Imposed population" risk determination approach. This approach actually assumes accident certainty.

\section{Problem formulation and modeling approach to solving RLIRPUR}

The problem studied in this paper can be described as multi period deterministic reverse IRP of collecting one type of $\mathrm{HM}$ recyclables with the objective to provide continuous supply of the recycling facility under minimal transport costs, while minimizing transportation and recyclables storing risk.

Expected quantities $\mathrm{q}_{\mathrm{it}}=\mathrm{q}_{\mathrm{i}}$ of recyclables collected every day $t=1, \ldots, T$, during the observed planning horizon $\mathrm{T}$ are constant, and known in advance, for each of collection points $i \in \mathrm{I}$ from the set I. Collection points are equipped with appropriate containers of known capacity $D_{i}=q_{i} \tau_{i}$, which is large enough to accept all collected quantities during the period of $\tau_{\mathrm{i}}$ days. Recyclables can be transported by the fleet 
of $k \in \mathrm{K}$ vehicle types, of known capacities $\mathrm{q}_{\mathrm{k}}$. Vehicle fleet is of unlimited size, and therefore all deliveries can be realized. Collection points supply only one treatment facility which has known daily recycling capacity P. Of course, through the longer period, sum of all recyclables collected should be equal to the total materials recycled. All distances $d_{i d}$ between collection point $i$ and recycling facility, representing shortest paths are known. Recycling facility is equipped with a storage space of capacity $S_{P}$. To provide continuous recycling, inventory level in the storage at recycling facility site can't fall to zero. Inventory costs can be neglected, while transportation costs depend on travel distance. As collected recyclables belong to HM imposing risk that can be calculated by using equations (2) and (3).

$$
\begin{aligned}
& \operatorname{Min} \sum_{\mathrm{t}} \sum_{\mathrm{i}} \sum_{\mathrm{k}} \mathrm{c}_{\mathrm{k}} \mathrm{x}_{\mathrm{ik}} \mathrm{d}_{\mathrm{i}} \\
& \operatorname{Min} \sum_{t} \alpha_{P} \pi\left[\left(S_{P}^{0}-t \cdot P+\frac{P}{2}\right)+\sum_{i} \sum_{k} x_{t i k} q_{k}\right] \\
& +\sum_{t} \sum_{i} \alpha_{i}^{F} \pi\left[\left(S_{i}^{0}-\sum_{z=1}^{t} \sum_{k} x_{z i k} q_{k}+\sum_{k} \frac{x_{t i k} q_{k}}{2}\right)+q_{i}\right] \\
& +\sum_{t} \sum_{i} \sum_{k} \alpha_{i}^{T} x_{t i k}\left(2 r_{k} d_{i}+\pi r_{k}^{2}\right)
\end{aligned}
$$

st.

$$
\begin{aligned}
& \mathrm{S}_{\mathrm{P}}^{0}+\sum_{\mathrm{t}=1}^{\mathrm{z}} \sum_{\mathrm{i}} \sum_{\mathrm{k}} \mathrm{x}_{\mathrm{tik}} \mathrm{q}_{\mathrm{k}}-(\mathrm{z}-1) \mathrm{P} \leq \mathrm{S}_{\mathrm{P}} \quad \forall \mathrm{z} \in \mathrm{T} \\
& \mathrm{S}_{\mathrm{P}}^{0}+\sum_{\mathrm{t}=1}^{\mathrm{z}} \sum_{\mathrm{i}} \sum_{\mathrm{k}} \mathrm{x}_{\mathrm{tik}} \mathrm{q}_{\mathrm{k}}-\mathrm{z} \mathrm{P} \geq \mathrm{P} \quad \forall \mathrm{z} \in \mathrm{T} \\
& S_{i}^{0}+\sum_{t=1}^{\mathrm{z}} q_{i}-\sum_{t=1}^{z-1} \sum_{k} x_{t i k} q_{k} \leq D_{i} \quad \forall i \in I \quad \forall \mathrm{z} \in T \\
& S_{i}^{0}+\sum_{\mathrm{z}=1}^{t} q_{i}-\sum_{z=1}^{t} \sum_{k} x_{z i k} q_{k} \geq 0 \quad \forall i \in I \quad \forall \mathrm{z} \in T
\end{aligned}
$$

$\mathrm{x}_{\mathrm{tik}} \in \mathrm{N} \cup\{0\} \quad \forall \mathrm{i} \in \mathrm{I} \quad \forall \mathrm{t} \in \mathrm{T} \quad \forall \mathrm{k} \in \mathrm{K}$

Mentioned RLIRPUR can be formulated in following way.

Where

$i$ collection points

$t, z$ time period or day in the planning horizon $\mathrm{T}$

$d_{i}$ transport distance between the treatment faculty and collection point $\mathrm{i}$

$k$ vehicle type

$q_{k}$ capacity of the k-th type of the vehicle

$c_{k}$ transport costs of the $\mathrm{k}$-th vehicle type per unit distance

$S^{0}{ }_{P} \quad$ stock level in recycling facility storage at the beginning of observed interval

$S^{0}{ }_{i} \quad$ stock level in collection point at the beginning of observed interval

$P$ daily recycling capacity

$q_{i}$ expected quantity of recyclables collected during the day at the collection point $i$

$x_{t i k}$ number of vehicles of type $\mathrm{k}$ transporting recyclables from collection point $i$ during the day $\mathrm{t}$ - decision variable

$\alpha_{p^{\prime}} \alpha_{i^{\prime}}^{F} \alpha_{i}^{T}$ density of exposed receptors around recycling site, i-th collection point and shortest path from collection point i to treatment facility, respectively

$\pi$ Ludolf number (PI)

$r_{k}$ radius of spread of $\mathrm{HM}$ recyclable when transported by the vehicle with capacity of $q_{k}$

$\beta$ percentage of allowed difference between number of deliveries in different days

The objective function (4) tries to minimize total transport costs of supplying recycling facility from all collection points, during the observed planning horizon. The objective function (5) tries to minimize total transportation and recyclables storing risk $\mathrm{n}$ reverse logistics network. The first term in (5) represents risk imposed by average inventory level of $\mathrm{HM}$ at recycling facility, the second represents total risk imposed by average inventory level of $\mathrm{HM}$ at all of collection points, while the third represents total transportation risk. Constraints (6) limit maximal quantity of recyclables at the recycling facility up to the storage capacity in each of observed intervals. Constraints (7) provide continuity of recycling process by preventing inventory level to fall below the quantity needed for the process realization in each of observed days. Constraints (8) limit maximal quantity of recyclables at collection points up to the capacity of containers in each of observed intervals. Constraints (9) prevent supply from the collection point i when inventory level of recyclables is lower than the 
capacity of supplying vehicle, in each of observed intervals. Constraint (10) define domains of decision variable.

Note, that model (4)-(10) could be widened with additional risk equalizing constraints:

$$
\begin{aligned}
& \alpha_{i}^{\mathrm{F}} \pi\left[\left(\mathrm{S}_{\mathrm{i}}^{0}-\sum_{\mathrm{z}=1}^{\mathrm{t}} \sum_{\mathrm{k}} \mathrm{x}_{\mathrm{zik}} \mathrm{q}_{\mathrm{k}}+\frac{\mathrm{x}_{\text {tik }} \mathrm{q}_{\mathrm{k}}}{2}\right)+\mathrm{q}_{\mathrm{i}}\right] \leq \\
& \frac{1-\gamma}{\mathrm{T}} \sum_{\mathrm{i}} \alpha_{\mathrm{i}}^{\mathrm{F}} \pi\left[\left(\mathrm{S}_{\mathrm{i}}^{0}-\sum_{\mathrm{z}=1}^{\mathrm{t}} \sum_{\mathrm{k}} \mathrm{x}_{\mathrm{zik}} \mathrm{q}_{\mathrm{k}}+\frac{\mathrm{x}_{\text {tik }} \mathrm{q}_{\mathrm{k}}}{2}\right)+\mathrm{q}_{\mathrm{i}}\right]
\end{aligned}
$$

$\forall \mathrm{i} \in \mathrm{I} \quad \forall \mathrm{z} \in \mathrm{T}$

$$
\begin{aligned}
& \alpha_{\mathrm{i}}^{\mathrm{T}} \mathrm{y}_{\text {tik }}\left(2 \mathrm{r}_{\mathrm{k}} \mathrm{d}_{\mathrm{i}}+\pi \mathrm{r}_{\mathrm{k}}^{2}\right) \leq \frac{1-\delta}{\mathrm{T}} \sum_{\mathrm{t}} \sum_{\mathrm{i}} \alpha_{\mathrm{i}}^{\mathrm{T}} \mathrm{y}_{\text {tik }} \\
& \left(2 \mathrm{r}_{\mathrm{k}} \mathrm{d}_{\mathrm{i}}+\pi \mathrm{r}_{\mathrm{k}}^{2}\right) \quad \forall \mathrm{i} \in \mathrm{I} \quad \forall \mathrm{t} \in \mathrm{T}
\end{aligned}
$$

In this case inequalities (11) can be used to equalize risk levels at collection facilities, defining maximal allowable deviation from the average risk level, where value of $0 \leq \gamma \leq 1$ defines percentage of deviation. Also, inequalities (12) can be used to equalize risk levels in transportation, defining maximal allowable deviation from the average risk level, where value of $0 \leq \delta \leq 1$ defines percentage of deviation, $\gamma$ percentage of allowed difference in the risk levels among collection facilities, $\delta$ percentage of allowed difference in the risk levels among transportation paths, while binary variable ytik is defined in following way

$\mathrm{y}_{\mathrm{tik}}=\left\{\begin{array}{l}1 \text { if recyclables are transported from collection point } \mathrm{i} \\ \text { by the vehicle of type } \mathrm{k} \text { during the day } \mathrm{t} \\ 0 \text { otherwise }\end{array}\right.$

Similarly, it is also possibly to introduce inequalities (13) to equalize quantity of recyclables delivered each day in considered interval, defining maximal allowable deviation from the average delivered quantity, where value of $0 \leq \beta \leq 1$ defines percentage of deviation.

$\sum_{\mathrm{i}} \sum_{\mathrm{k}} \mathrm{x}_{\mathrm{tik}} \leq \frac{1+\beta}{\mathrm{T}} \sum_{\mathrm{t}} \sum_{\mathrm{i}} \sum_{\mathrm{k}} \mathrm{x}_{\mathrm{tk}} \quad \forall \mathrm{t} \in \mathrm{T}$

\section{Numerical example and computational results}

Testing the quality of proposed approach for solving the RLIRPUR has been tested on the following numerical example. The number of collection points was $\mathrm{I}=6$, and the planning horizon was $\mathrm{T}=5$ days (numerical example was based on the reverse logistic system shown in Figure 1). Recyclables transportation was realized by the fleet with two vehicle types of capacities $0.5 \mathrm{t}$, and $1 \mathrm{t}$ which risk radii were 0.1 , and $0.2 \mathrm{~km}$. Unit transportation cost for th vehicle of larger capacity was 1.5 unit per kilometer, and for the smaller 1 unit per kilometer. Inventory level at the recycling site, at the beginning of observed interval was $6 \mathrm{t}$, storage capacity $30 \mathrm{t}$, and recycling rate $6 \mathrm{t}$ daily. Quantities collected during the day at each collection point varied between $1.5 \mathrm{t}$ for collection points 1 and $5 ; 1 \mathrm{t}$ at collection points 4 and 6 , and $0.5 \mathrm{t}$ at nodes 2 and 3. Storage capacities at all of collection points were 20t. Distances from collection points to the recycling facility are $3.9,2.9,3.7,3.5,4.1$ and $3.1 \mathrm{~km}$ respectively for nodes 1 to 6 . All densities of exposed receptors multiplied by $\mathrm{p}$ have value 1 .

Mathematical model (4) - (10) described above was implemented through the open source LP Solve 5.15, and solving time on ASUS laptop with DualCore Turion $2.66 \mathrm{GHz}$ was lesser then $1 \mathrm{sec}$. This small size problem has 62 variables, and 66 constraints.

As an illustration, results of the model application, for different objective functions, are presented in the Table 1 and Table 2. Columns "I" represent collected (in case of collection points), or total received quantities (in case of recycling facility). Columns " $\mathrm{O}$ " in case of collection points represents supplying quantities, and daily consumption rate for recycling facility. Columns " $\mathrm{S}$ " represent inventory levels at the end of the day (observed interval).

\section{Conclusion}

Environmental concerns, legislative measures and growing public awareness about the environmental consequences of waste disposal and extraction of natural resources have led to an increase in recycling and reuse efforts. As a result, increasing intensities of reverse logistics flows introduce new requirements in designing and controlling processes in those networks. Since collection of discarded 
Table 1. Inventories ( $\mathrm{t})$, supply schedule and quantities in case of $0.5 \mathrm{t}$ and $1 \mathrm{t}$ vehicles under risk minimization criterion - costs 132.9 , risk 526

\begin{tabular}{|c|c|c|c|c|c|c|c|c|c|c|c|c|c|c|c|c|c|c|c|c|c|}
\hline \multirow{2}{*}{ Days } & \multicolumn{3}{|c|}{ Collect. point 1} & \multicolumn{3}{|c|}{ Collect. point 2} & \multicolumn{3}{|c|}{ Collect. point 3} & \multicolumn{3}{|c|}{ Collect. point 4} & \multicolumn{3}{|c|}{ Collect. point 5} & \multicolumn{3}{|c|}{ Collect. point 6} & \multicolumn{3}{|c|}{ Recycl. Fac } \\
\hline & 1 & 0 & $S$ & 1 & 0 & $S$ & 1 & 0 & $S$ & I & 0 & $S$ & 1 & 0 & $S$ & 1 & 0 & $S$ & I & 0 & $S$ \\
\hline 0 & & & 20.0 & & & 20.0 & & & 20.0 & & & 20.0 & & & 20.0 & & & 20.0 & & & 20.0 \\
\hline 1 & 1.5 & & 21.5 & 0.5 & & 20.5 & 0.5 & & 20.5 & 1 & & 21.0 & 1.5 & & 21.5 & 1 & $6 \times 1$ & 15.0 & $6 \times 1$ & 6 & 20.0 \\
\hline 2 & 1.5 & & 23.0 & 0.5 & $4 \times 1$ & 17.0 & 0.5 & & 21.0 & 1 & & 22.0 & 1.5 & & 23.0 & 1 & $2 \times 1$ & 14.0 & $6 \times 1$ & 6 & 20.0 \\
\hline 3 & 1.5 & & 24.5 & 0.5 & $6 \times 1$ & 11.5 & 0.5 & & 21.5 & 1 & & 23.0 & 1.5 & & 24.5 & 1 & & 15.0 & $6 \times 1$ & 6 & 20.0 \\
\hline 4 & 1.5 & & 26.0 & 0.5 & $11 \times 1$ & 1.0 & 0.5 & & 22.0 & 1 & & 24.0 & 1.5 & & 26.0 & 1 & & 16.0 & $11 \times 1$ & 6 & 25.0 \\
\hline 5 & 1.5 & & 27.5 & 0.5 & $1 \times 1$ & 0.5 & 0.5 & & 22.5 & 1 & & 25.0 & 1.5 & & 27.5 & 1 & & 17.0 & $1 \times 1$ & 6 & 20.0 \\
\hline
\end{tabular}

Table 2. Inventories ( $\mathrm{t}$ ), supply schedule and quantities in case of $0.5 \mathrm{t}$ and $1 \mathrm{t}$ vehicles under risk minimization criterion - costs 210.6 , risk 454.5

\begin{tabular}{|c|c|c|c|c|c|c|c|c|c|c|c|c|c|c|c|c|c|c|c|c|c|}
\hline \multirow{2}{*}{ Days } & \multicolumn{3}{|c|}{ Collect. point 1} & \multicolumn{3}{|c|}{ Collect. point 2} & \multicolumn{3}{|c|}{ Collect. point 3} & \multicolumn{3}{|c|}{ Collect. point 4} & \multicolumn{3}{|c|}{ Collect. point 5} & \multicolumn{3}{|c|}{ Collect. point 6} & \multicolumn{3}{|c|}{ Recycl. Fac } \\
\hline & 1 & 0 & $S$ & 1 & 0 & $S$ & 1 & 0 & $S$ & 1 & 0 & $S$ & 1 & 0 & $S$ & 1 & 0 & $S$ & I & 0 & $S$ \\
\hline 0 & & & 20.0 & & & 20.0 & & & 20.0 & & & 20.0 & & & 20.0 & & & 20.0 & & & 20.0 \\
\hline 1 & 1.5 & & 21.5 & 0.5 & $3 \times 1$ & 17.5 & 0.5 & & 20.5 & 1 & $21 \times 1$ & 0.0 & 1.5 & & 21.5 & 1 & & 21.0 & $24 \times 1$ & 6 & 38.0 \\
\hline 2 & 1.5 & & 23.0 & 0.5 & $6 \times 1$ & 12.0 & 0.5 & & 21.0 & 1 & & 1.0 & 1.5 & & 23.0 & 1 & & 22.0 & $6 \times 1$ & 6 & 38.0 \\
\hline 3 & 1.5 & & 24.5 & 0.5 & $6 \times 1$ & 6.5 & 0.5 & & 21.5 & 1 & & 2.0 & 1.5 & & 24.5 & 1 & & 23.0 & $6 \times 1$ & 6 & 38.0 \\
\hline 4 & 1.5 & $6 \times 1$ & 20.0 & 0.5 & & 7.0 & 0.5 & & 22.0 & 1 & & 3.0 & 1.5 & & 26.0 & 1 & & 24.0 & $6 \times 1$ & 6 & 38.0 \\
\hline 5 & 1.5 & & 21.5 & 0.5 & & 7.5 & 0.5 & & 22.5 & 1 & & 4.0 & 1.5 & & 27.5 & 1 & & 25.0 & & 6 & 32.0 \\
\hline
\end{tabular}

products represents a crucial activity in reverse logistics system, in this paper we discuss the idea and possible modeling approach to simultaneously solving problems of optimal quantity and time of delivery of HM recyclables, as well as the problem of optimal scheduling of vehicles. However, the objective of finding balance between inventory and transport costs is widened by introducing additional, risk criterions, transforming the IRP problem into the one kind of Reverse Logistics Inventory Routing Problems Under Risk.

The problem is formulated as Mixed integer linear programming model, with multiple objectives of: transport costs minimizing, facility, and transport risk minimizing. Although this paper presents an early research phase, proposed approach seems to be very promising and its further analyzing and improving can be viewed as a main direction of future research.

\section{Acknowledgments}

This work was partially supported by Ministry of Science and Technological Development Republic of Serbia, through the project TR 15018, for the period 2008-2010. 


\section{References}

Umeda, Y., Tsukaguchi, H., Li Y. (2003). Reverse logistics system for recycling: efficient collection of electrical appliances. - Proceedings of the Eastern Asia Society for Transportation Studies 4, pp. 1319-1334.

Thierry, M., Salomon, M., van Nunen, J., van Wassenhove, L.N. (1995). Strategic issues in product recovery management. - California Management Review 37, pp. 114135.

Bostel, N., Dejax, P., Lu Z. (2005) The design, planning and optimization of reverse logistics systems: a review. - In: A. Langevin and D. Riopel. (eds.): Logistics systems: Design and Optimization, Springer, pp. 171-212.

Beullens, P. (2001). Location, process selection, and vehicle routing models for reverse logistics. Ph.D. thesis, Katholieke Universiteit Leuven, Belgium.

Teixeira, J., Antunes, A. P., Sousa, J.P. (2004). Recyclable waste collection planning - a case study. European Journal of Operational Research pp. 543-54.

Poot, A., Kant, G., Wagelmans, A. P. M.:(2002). A savings based method for real-life vehicle routing problems. Journal of the Operational Research Society, pp. 57-68.

Le Blanc, H. M., Fleuren, H., Krikke, H. R. (2004). Redesign of a recycling system for LPG-tanks. OR Spectrum, pp. 283-304.

Krikke, H., le Blanc, I., van Krieken, M., Fleuren, H. (2008).Low-frequency collection of materiales disassembled from end-of-life vehicles. International Journal of Production Economics, pp. 209-228.

EPA. (1996).Managing Used Oil: Advice for Small Businesses. Report 530EPA-F-96-004,
European Parliament and Council. Directive 2000/53/EC of the European Parliament and of the Council of 18 September 2000 on end-of life vehicles. Official Journal of the European Communities. Web Reference:<http:// europa.eu.int/eurlex/pri/en/oj/dat/2000/1_269/ 1_26920001021en00340042.pdf>

Aras, N., Aksen. D., Tanagur.,A.G., (2008) Locating collection centers for incentive-dependent returns under a pick-up policy with capacitated vehicles -European Journal of Operational Research 191, pp. 1223-1240

Erkut, E., Tjandra, S., Verter, V., (2007), “Hazardous Materials Transportation" Chapter 9 in: C. Barnhart and G. Laporte (Eds.), Handbook in OR \& MS, Vol. 14, Elsevier B.V.

Morrell, D. (1984). Siting and the Politics of Equity. Hazardous Waste pp. 555-571.

Keeney, R. L. (1980). Equity and Public Risk. Operations Research 28, pp. 527-534.

Current J., Ratick S. (1995) A model to assess risk, equity and efficiency in facility location and transportation of hazardous materials, Location Science 3 (3), pp. 187201.

Jayaraman, V., Patterson, R.A., Rolland, E., (2003). The design of reverse distribution networks: Models and solution procedures. European Journal of Operational Research 150, pp. 128-149.

Batta, R., Chiu, S.S., (1988). Optimal obnoxious paths on a network: Transportation of hazardous materials, Operations Research 36 (1), pp. 84-92

Milorad Vidovic was born in Belgrade, Serbia in 1957, where he finished elementary and high school. He graduated from the University of Belgrade, at Faculty of transport and traffic engineering, where took PhD dissertation in 1998. He works at the same University, at Logistics department since 1987. Since December 2005 he became associate professor at Logistics department, teaching courses in "Materials handling", "Simulation of logistic systems" and "Reverse logistics" on undergraduate level. At the master level studies he teaches courses "Operational planning of material handling processes", and "Advance topics in reverse logistics". On PhD studies he teaches courses "Supply chains", and "Material handling systems". During years 2000 and 2001 he worked as visiting assistant professor at Pusan National University, Busan South Korea and Korean advanced institute of science and technology in Daejeon, South Korea. From 2004 to 2008 was engaged as visiting professor at Logistics department of Izmir University of economy, Izmir, Turkey. His research interest is related to modeling and application of quantitative and operations research methods in logistics. He participated and conducted numerous research projects, supervised several master and PhD thesis, and is author of two books and more than 80 papers published in journals and conference proceedings.

Branislava Ratkovic is working since 2007 as a Research and Teaching Assistant at Faculty of Transport and Traffic Engineering, University of Belgrade. She has obtained both Bachelor and of Master of Science degree in 2006 at Faculty of Traffic and Transport Engineering, Department of Logistics. Currently, she is teaching courses in Material Handling, Goods in Logistics Systems and Reverse Logistics and Closed Loop Supply Chains. At the same time, she has been enrolled as Doctoral student at the Faculty of Transport and Traffic Engineering, University of Belgrade. Her interests are materials handling, optimization techniques and heuristics, performances of logistics systems. Especially, her current focuses of research are strategic issues in reverse logistics and closed loop supply chains. She participated at five research projects and she is co-author at 15 scientific papers. 
Nenad P. Bjelic is a Research and Teaching Assistant at the University of Belgrade, Faculty for Transport and Traffic Engineering where he is engaged in undergraduate courses "Material handling systems" and "Object oriented simulation", as well as on graduate course "Operational control of material handling systems". He received M.Sc. degree from the same faculty at the Department for Logistics by defeating thesis related with operational control of material handling devices. Currently he is Ph.D. candidate at the Faculty for Transport and Traffic Engineering. Research areas he is interested in are related with implementation of different operations research methods, such as simulation, linear programming, heuristic and metaheuristic algorithms, in solving operational level logistics problems.

Drazen Popovic has been working since 2008. as a Teaching Assistant at Department of Logistics, Faculty of Transport and Traffic Engineering, University of Belgrade where he obtained both Bachelor degree and degree of Master of Science in 2005. He has been teaching courses in Supply Chains, Material Handling and currently is teaching courses in Object Oriented Simulations, Management of Informations in Logistics, Logistic Performances and Controlling, Geographic Information Systems, Modeling of Performances in Logistics Systems. At the same time he enrolled PhD studies in 2008. at the Faculty of Transport and Traffic Engineering, University of Belgrade. His interests are materials handling, optimization techniques and heuristics, simulation and programming, performances of logistics systems. Main topic of his future doctoral thesis is inventory routing problem (IRP) in distribution of different types of goods, considering both deterministic and stochastic models 